Part of Journal of Research of the National Bureau of Standards, Volume 16, February 1936

\title{
ACTION OF “HYPO” SOLUTION ON STONE TANKS
}

\author{
By Daniel W. Kessler
}

\section{ABSTRACT}

The resistance of five types of natural stone to "hypo" solutions has been studied under conditions simulating those in hypo tanks. For stones of high resistance to acid attack, the destructive action is mainly physical and is caused by the salts crystallizing in the pores of the stone above the solution level. The resistance of the samples was studied in relation to certain physical properties, and a specification is suggested which would probably obtain suitable stone for hypo tanks.

\section{CONTENTS}

I. Introduction

II. Stone samples_.

III. Description of tests _.

IV. Results of tests

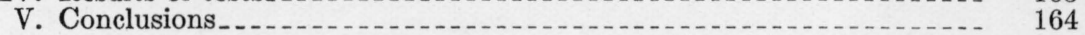

\section{INTRODUCTION}

The destructive action of hypo solutions on tanks is well known to operators of photographic shops. Wood and some varieties of natural stone have been commonly used for large hypo tanks, but apparently the same kind of destructive action occurs on both materials. One case has been noted in which a stone tank was in an advanced state of disintegration after 3 years of service. Another case, in which a different variety of stone was used, shows reasonably good service, as the tank has been in use for 18 years. Three sides of this tank have deteriorated considerably, and one is still in good condition.

The tanks are usually filled about half full of the solution, which penetrates into the pores of the stone, and crystals of the salts may form from the liquid level to the top of the tank because the solution is drawn upward by capillarity. In the denser stones this crystallization manifests itself by a narrow band of spalling slightly above the solution, but in more porous materials the spalling may cover a larger area and even extend to the top. The spalling is usually more prominent on the inside of the tank, but it sometimes occurs on the outside also. Laboratory studies were undertaken to determine those properties of stone conducive to longer service and those which must be avoided. The solution contains acetic acid, and consequently calcareous materials should not be used. However, the difficulty is not 
necessarily one of securing a stone chemically resistant to hypo solution, since the destructive action is caused mainly by the salts crystallizing in the pores of the stone and creating sufficient pressure to cause spalling.

\section{STONE SAMPLES}

Five types of stone were selected for study, as follows: (1) talcose serpentine; (2) chloritic amphibole; (3) slate; (4) bluestone; and (5) soapstone.

The talcose serpentine has been used to a considerable extent for hypo tanks and some grades have given good service. Type (2) has had only a limited use in hypo tanks and, in one case at least, the results were unsatisfactory.

Types (3), (4), and (5) were included because they can be readily worked into suitable shapes for tank construction. Seven samples of talcose serpentine, nine of chloritic amphibole, two of bluestone, two of slate (one blue-gray and one green), and one of soapstone were exposed to the hypo solution. Cleavage was most pronounced in the slate, much less so in the bluestone, least in the chloritic amphibole, and absent in the serpentine and soapstone samples. Other physical properties of the various samples are given in table 1. The slates gave the highest strengths when tested perpendicular to the cleavage

$\mathrm{T}_{\mathrm{ABLE}}$ 1.-Physical properties and ratings of materials

\begin{tabular}{|c|c|c|c|c|c|c|}
\hline $\begin{array}{l}\text { Desig- } \\
\text { nation }\end{array}$ & Classification & $\begin{array}{l}\text { 48-hr. } \\
\text { absorp- } \\
\text { tion } 1\end{array}$ & $\begin{array}{c}\text { Abrasive } \\
\text { hard- } \\
\text { ness, } \\
\left(\mathrm{H}^{a}\right)\end{array}$ & $\begin{array}{c}\text { Modulus } \\
\text { of rup- } \\
\text { ture }^{3}\end{array}$ & $\begin{array}{c}\text { Bulk } \\
\text { density }\end{array}$ & $\begin{array}{l}\text { Observed } \\
\text { condition } \\
\text { after } \\
\text { test }{ }^{4}\end{array}$ \\
\hline $\begin{array}{l}\mathrm{A}_{1} \\
\mathrm{~A}_{2} \\
\mathrm{~B}_{1} \\
\mathrm{~B}_{3} \\
\mathrm{~B}_{3} \\
\mathrm{~B}_{4} \\
\mathrm{~B}_{5} \\
\mathrm{~B}_{6} \\
\mathrm{~B}_{7} \\
\mathrm{~B}_{8} \\
\mathrm{~B}_{9} \\
\mathrm{C}_{1} \\
\mathrm{C}_{2} \\
\mathrm{D}_{1} \\
\mathrm{D}_{2} \\
\mathrm{D}_{3} \\
\mathrm{D}_{4} \\
\mathrm{D}_{5} \\
\mathrm{D}_{6} \\
\mathrm{D}_{7} \\
\mathrm{E}\end{array}$ & 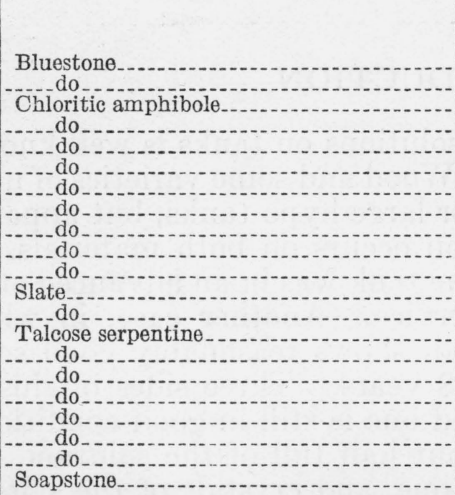 & $\begin{array}{c}\text { Weight } \\
(\%) \\
2.9 \\
2.5 \\
.18 \\
.18 \\
.14 \\
.18 \\
.18 \\
.15 \\
.22 \\
.17 \\
.15 \\
.35 \\
.12 \\
.20 \\
.06 \\
.07 \\
.07 \\
.09 \\
.20 \\
.14\end{array}$ & $\begin{array}{r}14.0 \\
13.6 \\
16.2 \\
7.8 \\
10.8 \\
12.6 \\
35.2 \\
10.8 \\
12.0 \\
12.0 \\
7.0 \\
7.7 \\
4.5\end{array}$ & $\begin{array}{r}\text { lb/ing } \\
2,000 \\
4,000 \\
8680 \\
3,500 \\
2,680 \\
6,240 \\
3,640 \\
6,240 \\
2,490 \\
5,900 \\
11,500 \\
10,800 \\
2,400 \\
2,380 \\
2,850 \\
5,680 \\
6,120 \\
4,450 \\
1,840 \\
1,920\end{array}$ & $\begin{array}{l}2.47 \\
2.47 \\
2.99 \\
2.97 \\
2.94 \\
2.97 \\
2.98 \\
2.97 \\
2.96 \\
2.96 \\
2.94 \\
2.78 \\
2.79 \\
2.87 \\
-2.96 \\
2.95 \\
2.85 \\
2.87 \\
2.87 \\
3.13\end{array}$ & $\begin{array}{l}e \\
d \\
d \\
d \\
c \\
c \\
c \\
c \\
c \\
c \\
c \\
d \\
b \\
c \\
c \\
a \\
a \\
a \\
a \\
d \\
c\end{array}$ \\
\hline
\end{tabular}

${ }_{1}$ Absorption test.-Specimens approximately 2 by 2 by 1 in. were dried at $105 \pm 2^{\circ} \mathrm{C}$ for 24 hours, allowed to cool for 30 minutes, weighed, then immersed in water at approximately $20^{\circ} \mathrm{C}$ for 48 hours. The final weights were determined after drying the surfaces of the specimens with a towel. The absorption values are expressed in percent by dividing the weight of water absorbed times 100 by the dry weight of tbe specimen.

${ }_{2}$ Abrasive hardness. - The tests were made on specimens measuring approximately 2 by 2 by 1 in. The apparatus and procedure are described in National Bureau of Standards Research Paper RP612, Wear Resistance of Natural Stone Flooring.

3 Flexure test.-Specimens approximately 12 by 2 by 1 in. were supported flatwise on knife-edges of the rocker type, spaced 10 in., on centers. Loads were applied through a third knife-edge at the center of span until rupture occurred. The modulus of rupture, $R$, was computed by means of the formula: $R=3 / 2\left(w 1 / b d^{2}\right)$, where $w=$ load in pounds causing rupture; $1=$ span, in inches (distance between supporting knife-edges); $b=$ width of specimen, in inches; and $d=$ thickness of specimen, in inches.

"Samples showing no definite deterioration are rated " $\mathrm{a}$ ", those showing the greatest amount "e." Others are given intervening letters in accordance with their observed condition.

${ }^{b}$ Sample B was tested parallel to the cleavage. All other samples were tested perpendicular to the cleavage. 


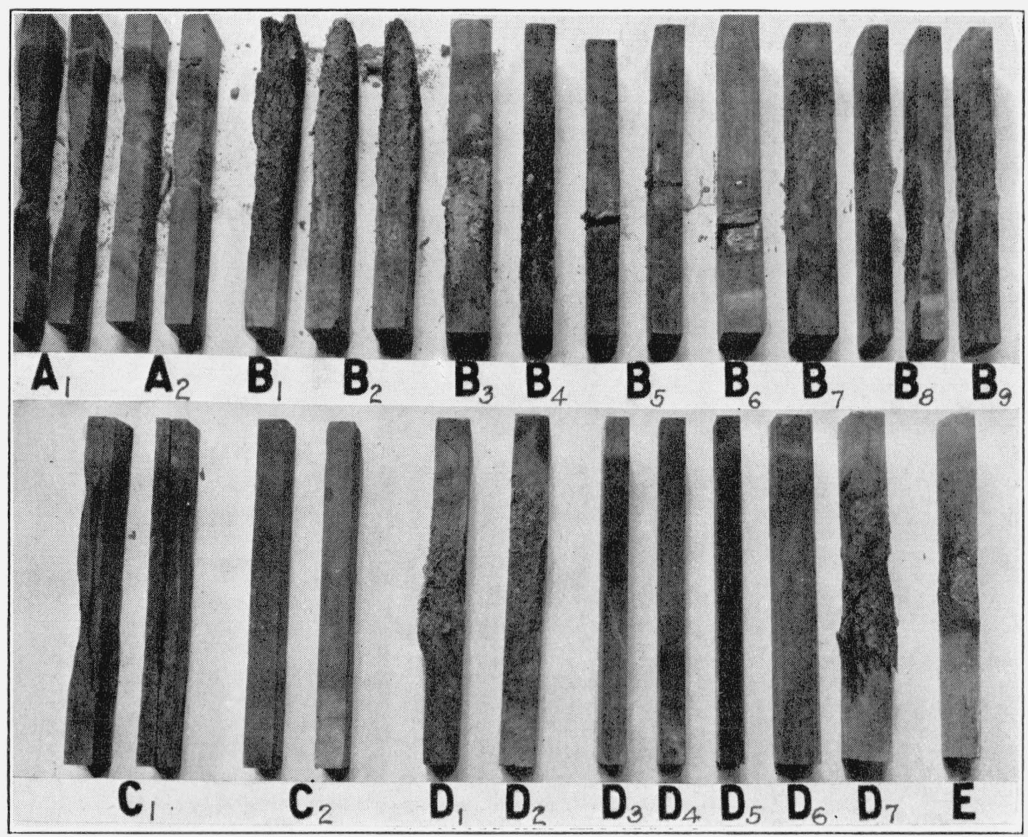

FIGURE 1.-Specimens of stone after exposure for 18 months to hypo solutions.

\section{Sample number}

$\mathrm{A}_{1}$ and $\mathrm{A}_{2}$

$\mathrm{B}_{1}$ and $\mathrm{B}_{0}$

$\mathrm{C}_{1}$ and $\mathrm{C}_{2}$

$\mathrm{D}_{1}$ to $\mathrm{D}$

$\mathrm{E}$

\section{Material}

Bluestone.

Chloritic amphibole. Slate.

Talcose serpentine. Soapstone. 
plane but if they had been broken along the cleavage plane, the values would have been very low. One chloritic amphibole sample $\left(B_{1}\right.$, table 1$)$ was broken in the cleavage direction, and the strength was shown to be low.

\section{DESCRIPTION OF TESTS}

The experiments were made on specimens measuring approximately 12 by 2 by 1 in. All specimens having definite cleavage were cut with the cleavage plane parallel to the long dimension except three of the chloritic amphibole specimens (two of $\mathrm{B}_{5}$ and one of $\mathrm{B}_{6}$ ), which were cut with the cleavage perpendicular to the long dimension. The specimens were placed on end in glass vessels in which a depth of about 4 in. of hypo solution was maintained. This exposure was intended to simulate the condition in hypo tanks. The hypo solution used in photographic shops is as follows:

\section{Solution A:}

1 part of sodium thiosulphate.

4 parts of water.

Solution B:

360 grams of sodium sulphite.

315 grams of glacial acetic acid.

360 grams of potassium alum.

Add water enough to make 4 liters.

One part of solution B is added to eight parts of solution A. Since the hypo solution in actual use becomes contaminated with silver halides from the developed photographic emulsion, the solution used in the tests was made up of one part of used solution, taken from a tank in the photographic shop, and two parts of freshly made solution.

The conditions of the test are believed to have been more severe than those in service, because the specimens could absorb the solution from five faces, while in tanks only one face is exposed to the solution. As some of the specimens had prominent cleavage the test conditions for such materials were more severe than for materials without cleavage, because absorption may occur more freely in the cleavage direction.

\section{RESULTS OF TESTS}

Within a short time the salts from the hypo solution formed incrustations on the specimens above the liquid level. After 6 months the bluestones were crumbling at the corners to a depth of about one-fourth inch and to a slight depth on the cleavage faces. The dark-colored slate developed cracks along the cleavage planes. After 12 months the bluestone, dark slate, and some of the chloritic amphibole specimens were in an advanced state of decay. The bluestones failed by flaking and crumbling, which occurred from the solution level upward for about 4 in. The dark slates showed two types of disintegration, one which caused the specimens to split along the cleavage, and the other which loosened splintery fragments from the corners and cleavage faces. The green slates showed only a small amount of scaling, while most of the chloritic amphibole specimens flaked on their cleavage faces, and some of the talcose serpentines scaled to an appreciable depth.

The test was discontinued at the end of 18 months, at which time all specimens, except four talcose serpentines $\left(D_{3}, D_{4}, D_{5}\right.$, and $\left.D_{6}\right)$, showed definite disintegration. The final condition is illustrated in 
figure 1, and a rating based on the relative amount of disintegration is given in table 1. Samples showing no definite deterioration are rated "a", and those showing the greatest amount "e". Others are given intervening letters in accordance with their observed conditions.

\section{CONCLUSIONS}

The physical property of stone which appears to be most determinative of resistance to hypo solutions is porosity. All of the samples rated "a" and "b" have absorption values of 0.12 percent, or less.

Abrasive hardness seems to have no effect on the resistance to disintegration, but it might be desirable, from other points of view, to employ hard materials, as they would be less apt to become scratched or worn.

Although the results do not show a definite relation between strength and resistance, this may be due to the fact that strength values were determined in only one direction for each sample. Except in the case of the green slate, all samples having cleavage effects showed poor resistance to hypo solution. Since this slate had a much less pronounced fissility than the dark slate, it may be inferred that a high flexural strength may offset, to some extent, the effects of cleavage.

Based on the results of this study, the following quality specification is suggested for stone hypo tanks: The stone shall be highly resistant to acids and free from cleavage; the flexural strength (modulus of rupture) shall be not less than $2,800 \mathrm{lb} / \mathrm{in} .{ }^{2}$; and the absorption shall be not more than 0.12 percent. Obviously this specification would not admit slate on account of its cleavage. If the degree of fissility could be measured it might be possible to formulate a specification which would obtain slate, such as $\mathrm{C}_{2}$, giving good service in hypo tanks.

Washington, December 27, 1935. 